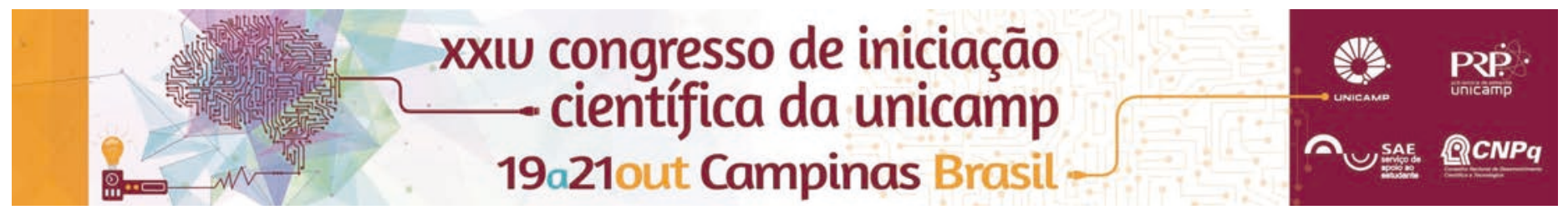

\title{
PROJETO E CONSTRUÇÃO DE HABITAÇÃO DE INTERESSE SOCIAL AUTOGERIDA - UMA ABORDAGEM BASEADA EM CONCEITOS DE PRODUÇÃO MAIS LIMPA.
}

\section{Letícia Caroline S. Oliveira*, Lucas Emanoel V. Z. Peruzza, Guilherme C. Romão, Matheus V. Silva}

\section{Resumo}

Combater o problema da inadequação da estrutura física da moradia autoconstruída, assim como o tratamento dos Resíduos de Construção Civil (RCC) provenientes destes eventos informais, é um grande desafio para Técnicos, Estado, Universidades e a Sociedade. Durante o PIBIC-EM tivemos a oportunidade de conhecer esse processo de produção habitacional, através de ações de pesquisa socioeconômica e espacial, coleta de RCC, cadastramento das habitações e produção de componentes agregando o RCC coletado. Utilizamos programas como o SketchUp, Gimp, Photoshop e Pix4D, para elaborar o cadastramento da habitação autoconstruída, cujos resultados serão apresentados neste artigo.

\section{Palavras-chave:}

Resíduos da Construção Civil, Tecnologias Digitais, Habitação Social.

\section{Introdução}

A autoconstrução sem assistência técnica resulta em condições precárias de infraestrutura física das habitações (problemas estruturais, funcionais e de salubridade). Além disso, a ausência de projetos e acompanhamento técnico na concepção e execução são as principais causas das elevadas taxas de desperdícios de materiais e consequentemente geração de RCC.

$O$ estudo realizado neste Projeto aborda essas questões, através de uma pesquisa exploratória, desenvolvida no Bairro Geada em Limeira (SP), composto por 380 lotes do programa "Lotes Urbanizados", nos quais os moradores planejam, projetam e constroem suas casas sem qualquer suporte técnico. Este projeto teve por objetivos:

- Identificar a população alvo das ações e do RCC gerado;

- estudar a dinâmica construtiva do bairro;

- coletar, fazer a triagem do RCC coletado e definir traço de concreto para produzir blocos de pavimentação com substituição de agregados por RCC;

- Mapear as moradias usando fotografias aéreas e terrestres e programas gráficos e de modelagem;

\section{Resultados e Discussão}

Através da revisão bibliográfica, minicursos e seminários da equipe, além da aproximação com os moradores, foi possível uma imersão nos temas abordados na pesquisa que nos auxiliaram no seu desenvolvimento.

Juntamente com pesquisadores, técnicos da Prefeitura Municipal de Limeira, graduandos e pós-graduandos foi elaborado o planejamento das ações de pesquisa qualitativa (entrevistas semiestruturadas), assim como coletas de material em campo. A participação dos moradores na coleta de RCC não foi como se esperava, apenas $2 \%$ colaboraram.

Participamos de ensaios no Laboratório de Materiais do RCC coletado, visando definir o traço do concreto a ser usado na fabricação de blocos de pavimentação que serão empregados em um protótipo residencial. Chegouse a $20 \%$ de substituição de agregados por RCC.

Foram feitas algumas visitas para capturar a situação existente das moradias, criando um cadastro atualizado do bairro. Para isso empregamos imagens terrestres e aéreas coletadas com um Drone (Fig.1).

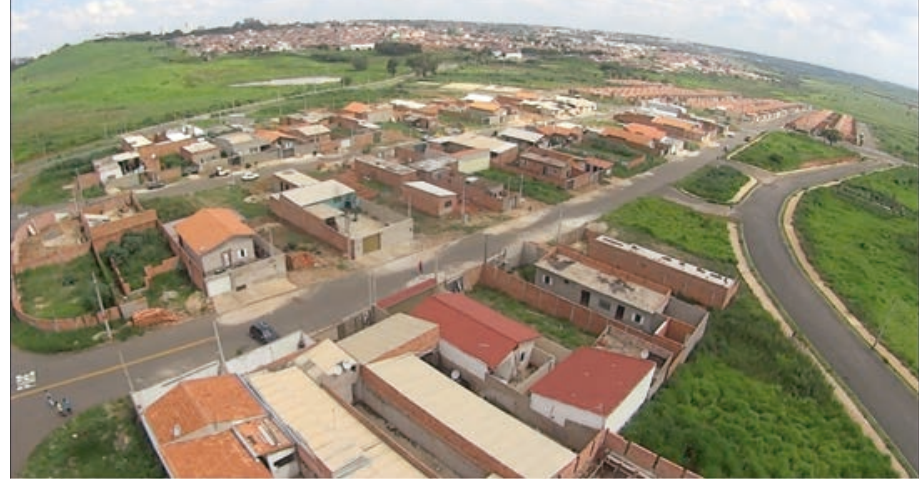

Figura 1. Foto aérea do bairro capturado com um drone.

Os vídeos foram trabalhados nos programas Photoshop (Adobe) e Pix4D, para gerar imagens estáticas. As imagens foram combinadas em montagens panorâmicas para reproduzir as faces das quadras estudadas. As imagens auxiliaram na elaboração da maquete 3D no programa SketchUP, criada com o intuito de ser uma interpretação dos resustados desta pesquisa e orientação para intervenções futuras no bairro.

\section{Conclusões}

Participar do programa PIBIC-EM nos ajudou a compreender melhor a questão habitacional e o desperdício de material construtivo quando usado sem orientação técnica. Assim como, através dos levantamentos, ensaios e modelagem, perceber a importância da Reciclagem, do uso de metodologias de Produção mais limpa em prol da melhoria das condições ambientais e de habitabilidade da população mais carente. Podemos concluir que os objetivos iniciais foram alcançados.

\section{Agradecimentos}

Agradecemos ao CNPq, à nossa orientadora e aos bolsistas SAE. 